\title{
ТРЕБОВАНИЯ, ОБЕСПЕЧЕННЫЕ ИПОТЕКОЙ ОБЪЕКТА НЕДВИЖИМОСТИ, СТРОИТЕЛЬСТВО КОТОРОГО НЕ ЗАВЕРШЕНО, КАК ЧАСТЬ ИПОТЕЧНОГО ПОКРЫТИЯ ИПОТЕЧНЫХ ОБЛИГАЦИЙ
}

\section{CLAIMS SECURED BY A MORTGAGE ON AN UNCOMPLETED PROPERTY AS PART OF THE MORTGAGE COVERAGE OF MORTGAGE BONDS}

\section{Kozlovsky}

Summary. The article is devoted to the question of the legal nature of the mortgage of an uncompleted real estate object that secures the claims included in the mortgage coverage of mortgage bonds, as well as in general the possibility of including such claims in the mortgage coverage. At the same time, mortgage bonds are an attractive investment tool due to high reliability of such securities. This makes them a potentially effective way for commercial banks to attract financing for mortgage lending as the cost of such financing is quite low. In turn, this can play a positive role in solving the problem of housing security in Russia due to the cost reduction of mortgage loans. While the inclusion of claims secured by the real estate the construction of which has not been completed in the mortgage coverage will give banks additional opportunities to issue mortgage bonds, allowing them to form mortgage coverage at a lower cost.

Keywords: mortgage bonds, mortgage coverage, mortgage of an incomplete real estate object, mortgage securities, residential real estate.

\section{Ввеление}

И потечные облигации являются разновидностью облигаций с залоговым обеспечением, которые в экономическом смысле призваны для использования коммерческими банками для целей получения дополнительного финансирования под выдачу ипотечных кредитов. При этом, их важной особенностью является высокий уровень надежности благодаря наличию качественного обеспечения, что приводит к низкой стоимости заимствований.

Таким образом, ипотечные облигации представляют собой привлекательный для бурно развивающегося фондового рынка инструмент, который одновременно способен предоставить коммерческим банкам недоро-

\author{
Козловский Михаил Сергеевич \\ Национальный исследовательский университет \\ «Высшая школа экономики», г. Москва \\ mkozlovsky56@gmail.com
}

Аннотация. Статья посвящена вопросу правовой природы ипотеки объекта недвижимости, строительство которого не завершено, обеспечивающей требования, включенные в ипотечное покрытие ипотечных облигаций, а также в целом возможности включения таких требований в ипотечное покрытие. При этом, ипотечные облигации представляются привлекательным инструментом для инвестирования, что обеспечивается высокой надежностью таких бумаг. Это делает их потенциально эффективным способом привлечения финансирования коммерческими банками для деятельности по выдаче ипотечных кредитов по причине низкой стоимости такого финансирования. В свою очередь, это может сыграть положительную роль при разрешении проблемы обеспеченности населения России жильем благодаря снижению стоимости ипотечных займов. Тогда как включение в состав ипотечного покрытия требований, обеспеченных залогом недвижимости, строительство которой еще не завершено, даст банкам дополнительные возможности по эмиссии ипотечных облигаций, позволив с меньшими издержками формировать ипотечное покрытие.

Ключевые слова: ипотечные облигации, ипотечное покрытие, ипотека объекта недвижимости, строительство которого не завершено, ипотечные ценные бумаги, жилая недвижимость.

гое финансирование для реализации задач по выдаче ипотечных кредитов гражданам, что может позитивно сказаться на решении проблемы обеспеченности населения России жильем.

Однако вследствие невысокой популярности данного инструменты в правовом регулировании остается множество пробельных моментов, одним из которых является вопрос включения требований, обеспеченных ипотекой объекта недвижимости, строительство которого не завершено, в ипотечное покрытие ипотечных облигаций. В частности, возникает проблема определения правовой природы ипотеки объекта недвижимости, строительство которого не завершено, в контексте ипотечных облигаций, а также возможности включения требований, обеспеченных таким способом, в ипотеч- 
ное покрытие ипотечных облигации. Этим вопросам и посвящена данная работа.

Понятие и экономическое значение ипотечных облигаций. Легальное определение облигаций с ипотечным покрытием дано в ст. 2 Закона об ипотечных ценных бумагах, которая определяет их как облигации, исполнение обязательств по которым обеспечивается полностью или в части залогом ипотечного покрытия.

Закон об ипотечных ценных бумагах не дает четкого и прямого определения (залога) ипотечного покрытия, называя лишь то имущество, которое может его составлять (ст.ст. 3 и 13), но его можно вывести из ряда норм ГК РФ, этого Закона и Закона об ипотеке (залоге недвижимости). При этом стоит отметить, какое имущество может входить в ипотечное покрытие: 1) обеспеченные ипотекой и (или) залогом прав требования участника долевого строительства требования о возврате основной суммы долга и (или) об уплате процентов по кредитным договорам и договорам займа, в том числе удостоверенные закладными, 2) ипотечные сертификаты участия, удостоверяющие долю их владельцев в праве общей собственности на другое ипотечное покрытие, 3) денежные средства в валюте Российской Федерации или иностранной валюте, 4) государственные ценные бумаги и недвижимое имущество (в случаях, указанных в Законе об ипотечных ценных бумагах) [3, ч. 1 ст. 3].

Прежде всего, ипотечное покрытие представляет собой вариант залогового обеспечения, из которого могут быть удовлетворены требования инвесторов к эмитенту в случае неисполнения или ненадлежащего исполнения обязательств по таким облигациям. При этом, существуют два способа для этого. Первый из них связан с продажей заложенного имущества с торгов, а вырученная с их помощью сумма уплачивается в счет требований кредитора [1, п. 1 ст. 350], а второй (также включенный в Закон об ипотеке) - с переводом в судебном порядке прав на ипотечное покрытие инвестору (в случае установления этого соглашением сторон) [1, п. 2 ст. 358.8 и 2, ст. 59.1].

Можно утверждать, что ипотечное покрытие является чаще всего вариантом залога прав, предусмотренного ст. 358.1 ГК [7, с. 357] (а также залога ценных бумаг при включении в ипотечное покрытие ипотечных сертификатов участия и залога вещей при включении недвижимости), реализация которого, в первом случае, осуществляется посредством продажи данного имущества с публичных торгов [1, п. 1 ст. 350], так как абз. 2 ч. 1 ст. 15 Закона об ипотечных ценных бумагах указывает на то, что обращение взыскания на требования и иное имущество, составляющие ипотечное покрытие облигаций, в том числе их реализация, осуществляется в по- рядке, предусмотренном Законом об ипотеке, тогда как п. 1 ст. 56 данного Закона предусматривает реализацию заложенного имущества путем его продажи с публичных торгов. Таким образом, можно отметить, что происходит переход прав требования от эмитента облигации к третьему лицу (покупателю на торгах) в отношении лица, являющемся должником (по договору займа или кредитному договору) перед эмитентом, если эмитент оказывается неисправным, а вырученная с помощью проведения таких торгов сумма идет в счет требований инвестора к эмитенту.

Однако во втором варианте право требования переходит к самому инвестору, который становится кредитором по отношению к должнику-третьему лицу [9, с. 372]. Стоит отметить, что таким образом к инвестору переходит не только право требования, но и ипотека, обеспечивающая исполнения данного долга $[1$, п. 1 ст. 384] в силу акцессорности залога, то есть инвестор становится залогодержателем не в отношении ипотечного покрытия, обеспечивавшего исполнение по облигации, а в отношении ипотеки недвижимости, обеспечивающей надлежащее исполнение собственником такой недвижимости своих обязательств перед новым кредитором - инвестором. Из этого вытекает возможность инвестора обратить взыскание на недвижимость должника по договору займа (кредита) как на предмет залога в случае, если этот должник не сможет исполнить надлежащим образом обязательство. Примерно так же дело обстоит с обращением взыскания на ипотечный сертификат участия и недвижимость.

Следовательно, ипотечное покрытие представляет собой совокупность указанного в Законе об ипотечных ценных бумагах имущества, в которое входят прежде всего права требования эмитента к должнику по договору займа (кредита) и обеспечивающая исполнение этих требований ипотека, и которое (имущество) является предметом залога для ипотечных облигаций, на которое может быть обращено взыскание инвестора в случае неисправности эмитента. Такую ситуацию Суханов Е.А. назвал «залогом залоговых прав» [8, с. 227], что в целом отражает проиллюстрированный механизм работы ипотечных облигаций, посредством которого, по сути, происходит «упаковка» прав требований и ипотеки в ипотечное покрытие (новый залог).

Помимо установления механизма работы ипотечных облигаций, также необходимо указать, в чем заключается экономическое значение данного инструмента. Как и для обеспеченных облигаций в целом основная цель эмиссии ипотечных облигаций заключается прежде всего в поисках альтернативного источника финансирования деятельности коммерческих организаций посредством инструментов, которые в большей степе- 
ни бы удовлетворяли интересам инвесторов. Большая привлекательность для инвесторов делает финансирование более доступным. Однако обеспечение в виде ипотечных активов таких облигаций предопределяет нескольку иную, более узкую и специфическую цель их эмиссии по сравнению с облигациями, имеющими иное обеспечение.

Прежде всего особенность заключается в том, кто может быть эмитентом таких облигаций. Закон императивно определяет, что осуществлять эмиссию облигаций с ипотечным покрытием могут только ипотечные агенты и кредитные организации [3, ч. 1 ст. 7]. То есть эмитенты таких бумаг - это организации, деятельность которых прямым образом связана с ипотечным кредитованием, что не удивительно, ведь формирование ипотечного покрытия в основном осуществляется благодаря ипотечному портфелю. В таком случае справедливо указать, что главная экономическая особенность заключается в том, что такие бумаги служат источником финансирования только для кредитных организаций, а не для любых «бизнесов».

Однако если посмотреть на более узкую картину, то можно прийти к выводу, что финансирование с помощью ипотечных облигаций осуществляется банками не просто с целью привлечения дополнительных средств как таковых, а с целью осуществления дальнейшего ипотечного кредитования, направления доходов от ипотечных ценных бумаг на формирования нового ипотечного портфеля, что является ключевым аспектом, определяющим экономический потенциал ипотечных облигаций [14].

Отталкиваться следует от того, что спрос на новое жилье в России крайне высокий вследствие необеспеченности населения жильем, что в целом представляет собой серьезную социальную проблему [10, с. 276-279]. Очевидно, что данный спрос должен удовлетворяться посредством приобретения нового жилья, что в подавляющем большинстве случаев означает использование ипотечного займа от коммерческих банков [12, с. 16]. Важность и серьезность проблемы осмыслена государством и даже в какой-то степени институционализирована посредством создания национального проекта «Жилье и городская среда», в соответствии с которым средняя ставка по ипотеке должна составлять в 2019 году $8.9 \%$, а к 2024-7.9\% [13, с. 2].

В данном случае ипотечные облигации и могут оказаться весьма полезными по двум причинам. Во-первых, стоимость финансирования, привлекаемого посредством эмиссии ипотечных облигаций, ниже, чем заимствования у Банка России или иных кредитных организаций $[11$, с. 86], а во-вторых, дополнительные средства, полученные от продажи таких ценных бумаг, позволят нарастить объем выдачи займов, что также может привести к снижению стоимости кредита для заемщиков. Стоит также отметить важность развития ипотечных облигаций для инвесторов, которые получают новый инструмент для вложения средств.

Проблема включения требований, обеспеченных ипотекой объекта недвижимости, строительство которого не завершено, в состав ипотечного покрытия. Излишне ограничивающим деятельность субъектов правоотношений, возникающих по поводу включения в ипотечное покрытие требований, обеспеченных ипотекой недостроенной недвижимости, являются взаимосвязанные положения абз. 1 и 3 ч. 3 ст. 3 Закона об ипотечных ценных бумагах. Думается, вначале следует сказать несколько слов о природе самой ипотеки незавершенной недвижимости.

i. По сути, то, что она представляет собой можно разделить на три категории. Во-первых, это может быть залог имущественных прав [1, п. 1 ст. 3581.], а именно прав требования залогодателя (должника в договоре займа) к застройщику по возведению соответствующего объекта недвижимости, что отвечает природе залога незавершенной недвижимости, так как пока объект не построен в том виде, в каком это оговорено в соответствующем договоре, и не зарегистрирован в надлежащем порядке, не существует никаких вещных прав залогодателя в отношении данного «объекта», а есть лишь имущественное право требования по возведению недвижимости, обязательственная относительная связь между застройщиком и залогодателем [9, с. 494]. В таком случае употребление формулировки «залог недвижимого имущества, строительство которого не завершено» совершенно некорректно, так как недвижимое имущество - это всегда вещь, а пока соответствующий объект не соответствует тому, что установлено в договоре, нельзя говорить о его существовании в качестве вещи.

Во-вторых, тем, о чем идет речь в указанном пункте, может быть объект незавершенного строительства, который представляет собой особую недвижимую вещь, технические характеристики и функциональные ограничения которой не позволяют отнести ее к полноценным объектам недвижимости вследствие невозможности использования ее в соответствии с теми целями, которым обыкновенно служит такая недвижимость. Однако данный вариант представляется наименее правильным вследствие того, что никак нельзя ожидать от сторон соответствующего договора цели включить в него в качестве предмета залога имущество такого рода, которое, строго говоря, имуществом может быть названо лишь с большой долей условности и экономи- 
ческая ценность которого стремиться к нулю и, скорее, соответствует стоимости тех стройматериалов, из которых оно было возведено (тогда получается, что предметом залога является совокупность строительных материалов, что является совсем уж абсурдным и явно не соответствующим цели обеспечения исполнения обязательств по выплате займа, выданного на приобретение недвижимости).

В-третьих, в указанном пункте может идти речь о залоге будущей вещи, то есть той, которая окажется в собственности залогодателя в будущем по одному из оснований, предусмотренному законом [1, п. 2 ст. 336]. Это отвечает как экономической цели сторон, которые получают некоторое имущественное обеспечение связывающего их обязательства, так и органично вписывается в текст вышеназванного пункта, имея в виду, что залог недвижимости, строительство которой не завершено,- - это лишь залог недвижимости, которая возникнет в будущем, а значит залогодатель получит ее в будущем.

Однако нормы ГК РФ о залоге указывают, что если предметом залога является имущество, которое будет создано или приобретено залогодателем в будущем, то залог возникает у залогодержателя с момента создания или приобретения залогодателем соответствующего имущества [1, п. 2 ст. 341]. Соответственно, ГК РФ оставляет временной промежуток, в который залогодержатель, по сути, не будет иметь никаких прав в отношении залога, который еще не возникнет (в данном случае - это время постройки объекта недвижимости).

Такая ситуация никак не может быть удовлетворительна для залогодержателя, которому, возможно, придется ждать весьма продолжительный срок, пока его право залога возникнет, тогда как обстоятельства, в соответствии с которыми ему может понадобиться обратить взыскание на предмет залога, могут наступить до истечения этого срока. В результате законодатель, дабы не допустить такой возможности в особо важных для правопорядка отношениях по ипотечному кредитованию, установил, что правила Закона об ипотеке (залоге недвижимости) применяются к залогу незавершенного строительством недвижимого имущества [2, п. 2 ст. 5].

Следовательно, залог в отношении будущей недвижимой вещи устанавливается, в отступление от правил ГК РФ, не с момента возникновения права собственности на такой объект у залогодателя, а ранее. Обращение взыскания же на такой предмет залога будет проводиться как на объект незавершенного строительства, право собственности на который застройщик обязан зарегистрировать (что означает воспринятие законом второго варианта толкования).
Но стоит отметить, что данный вариант толкования указанного пункта представляется не совсем корректным с точки зрения существа данных правоотношений по причине того, что сложно себе представить установление каких-либо прав в отношении несуществующего объекта, то есть, по сути, в отношении пустоты. Вполне может существовать обязательство (то есть «обещание») по передаче того или иного имущества в залог в будущем, однако установление самого залога, то есть прав залогодержателя в отношении заложенного имущества, невозможно без наличия самого имущества.

Однако уже в Законе об ипотечных ценных бумагах указано, что ипотечное покрытие могут составлять требования, обеспеченные в том числе и залогом прав требования участника долевого строительства [3, ч. 1 ст. 3]. Следовательно, правильное толкование, видимо, должно быть следующим: если приобретение недвижимости осуществлялось на основании договора участия в долевом строительстве, то такие требования попадают в ипотечное покрытие обеспеченными залогом прав по ДДУ, а если приобретение незавершенной недвижимости осуществляется не на основании дДУ, то при неисправности должника реализуется механизм обращения взыскания на объект незавершенного строительства (в ипотечное покрытие входят права требования, обеспеченные залогом «недвижимости»).

Тем не менее, в будущем представляется правильным подвергнуть данные положения изменениям, в соответствии с которыми залог будет возникать ранее, пока соответствующий объект недвижимости не достроен, всегда в отношении прав требования должника к застройщику, а после возведения недвижимости уже в отношении самой недвижимости в силу закона в качестве проявления динамики залоговых правоотношений.

ii. Итак, абз. 1 указанной статьи исключает возможность включения в состав ипотечного покрытия жилищзных облигаций требований, обеспеченных залогом недвижимого имущества, строительство которого еще не завершено [3, абз. 1 ч. 3 ст. 3]. Таким образом, законодатель позволяет включать такие требования в состав обеспечения нежилищных облигаций, но по какой-то причине делает исключение для жилищных. Вероятно, логика Закона заключается в том, что риск оказаться недостроенными у нежилых помещений ниже, чем у жилых, что может быть связано с несовершенными механизмами привлечения финансирования застройщиками для целей жилищного строительства. В частности, речь может идти об активном использовании договоров долевого участия, которые не гарантируют доведения процесса строительства до конца (достаточ- 
но вспомнить многочисленные истории «обманутых дольщиков» и примеры незавершенного строительства, которое вели обанкротившиеся и канувшие в лету застройщики). В результате законодатель решает перестраховаться и не допускать такие ненадежные активы в качестве обеспечения по массовым финансовым инструментам, которым являются ипотечные облигации.

Однако не так давно были приняты соответствующие поправки в законодательство, в результате которых механизм привлечения финансирования для строительства жилой недвижимости в виде договоров долевого участия был дополнен, и к нему было предложено использовать механизмы условного депонирования (эскроу) [6, п. 49 ст. 2; 4, ст.ст. 15.4 и 15.5]. Если кратко описать смысл соответствующих поправок, то теперь денежные средства лиц, заключивших договоры долевого участия, поступают не сразу застройщику, а переходят на соответствующий эскроу-счет данного застройщика в банке, который сможет получить их только в случае, если строительство будет завершено, а объекты недвижимости введены в эксплуатацию [4, ст.ст. 15.4 и 15.5]. Вместо денег покупателей соответствующей недвижимости строительным компаниям придется ориентироваться на собственные средства или привлечение банковского финансирования. Более того, привлечение денежных средств по договорам долевого участия в отношении недвижимости, строительство которой не завершено, после 1 июля 2019 года допускается только с использованием эскроу-счетов, за исключением тех объектов, которые соответствуют установленным Правительством критериям, определяющим степень готовности таких объектов и количество заключенных договоров долевого участия [5, ст. 16]. Очевидно, что в результате данных нововведений риск незавершения строительства жилых домов существенно снизился.

Таким образом, при текущем регулировании привлечения средств для финансирования строительства жилой недвижимости и имеющихся невысоких рисках возможного неисполнения застройщиком своих обязанностей не представляется целесообразным действующее излишне ограничительное и носящее перестраховочный характер правило на включение в ипотечное покрытие ипотечных облигаций требований, обеспеченных залогом недвижимого имущества, строительство которого не завершено. Положительный эффект на возможности эмитентов окажет отмена соответствующих ограничений и предоставление эмитентам права включать в ипотечное покрытие жилищных облигаций требований, обеспеченных залогом недостроенной недвижимости.

iii. Другой перестраховочный механизм заложен в абз. 3 ч. 3 ст. Закона об ипотечных ценных бумагах, и заключается он в том, что закон ограничивает право эмитентов на включение в ипотечное покрытие ипотечных облигаций требований, обеспеченных залогом недвижимости, строительство которой не завершено, десятью процентами от размера ипотечного покрытия. Очевидно, что сделано это законодателем с целью снизить риски попадания в ипотечное покрытие ненадежных активов, чтобы инвесторы могли получить полное удовлетворение по своим требованиям. Однако представляется, что десять процентов крайне небольшая доля, которая может существенно ограничивать заемщиков в возможности эмитировать ипотечные облигации, ведь для этого им может понадобиться больший пул требований по уже полностью построенной и сданной недвижимости, тогда как очевидно, что это процесс довольно долгий и сложный, а заметная доля ипотечных займов (в том числе коммерческих) выдается именно под недостроенную недвижимость.

Таким образом, для повышения возможностей эмитентов по выпуску ипотечных облигаций и получению дополнительного финансирования на их инвестиционную деятельность положительный эффект будет иметь некоторое увеличение возможной доли в ипотечном покрытии требований, обеспеченных ипотекой недвижимости, строительство которой не завершено, при сохранении разумных ограничений на включение таких требований по причине их меньшей надежности.

\section{Зак^ючение}

Приведенная выше попытка определения правовой природы ипотеки объекта недвижимости, строительство которого не завершено, в контексте ипотечных облигаций, а также возможности включения требований, обеспеченных таким способом, в ипотечное покрытие ипотечных облигации привели к следующим выводам.

Во-первых, если приобретение недвижимости, являющейся обеспечением по требованиям, входящим в ипотечное покрытие, осуществлялось на основании договора участия в долевом строительстве, то такие требования попадают в ипотечное покрытие обеспеченными залогом прав по ДДУ, а если приобретение незавершенной недвижимости осуществлялось не на основании ДДУ, то при неисправности должника реализуется механизм обращения взыскания на объект незавершенного строительства, тогда как сам объект необходимо зарегистрировать в таком ключе в Реестре. В дальнейшем законодателю стоит подвергнуть данные положения изменениям, в соответствии с которыми залог будет возникать всегда в отношении прав требования должника к застройщику, а после возведения недвижимости - уже в отношении самой недвижи- 
мости в силу закона в качестве проявления динамики залоговых правоотношений.

Во-вторых, включение требований, обеспеченных ипотекой недвижимости, строительство которой не завершено, в состав ипотечного покрытия жилищных облигаций de lege lata невозможно, что представляется ошибочным, так как в связи с принятыми законодательными изменениями, направленными на совершенствование механизмов строительства жилой недвижимости, риск оказаться недостроенной у такой недвижимости существенно снизился, что открывает дорогу для включения требований, обеспе- ченных таким способом, в состав ипотечного покрытия.

Также представляется чрезмерно ограничительным подход законодателя к объему включения в ипотечное покрытие нежилищных облигаций требований, обеспеченных ипотекой недостроенной недвижимости, так как это существенным образом снижает возможности эмитентов таких облигаций по привлечению средств данным способом, тогда как существующие риски явно преувеличены законодателем. Следовательно, необходимо увеличить допустимый объем соответствующих требований в составе ипотечного покрытия.

\section{ЛИТЕРАТУРА}

1. Гражданский кодекс Российской Федерации (часть первая) от 30.11.1994 N51-Ф3 (ред. от 09.03.2021) // СПС «ГаранТ».

2. Федеральный закон от 16.07.1998 N102-Ф3 «06 ипотеке (залоге недвижимости)» (редакция от 30.04.2021) // СПС «Гарант».

3. Федеральный закон от 11.11.2003 N152-Ф3 «06 ипотечных ценных бумагах» (редакция от 08.12.2020) // СПС «Гарант».

4. Федеральный закон от 30.12.2004 N214-Ф3 «0б участии в долевом строительстве многоквартирных домов и иных объектов недвижимости и о внесении изменений в некоторые законодательные акты Российской Федерации» (редакция от 30.04.2021) // СПС «Гарант».

5. Федеральный закон от 25.12.2018 N478-Ф3 «0 внесении изменений в Федеральный закон «0б участии в долевом строительстве многоквартирных домов и иных объектов недвижимости и о внесении изменений в некоторые законодательные акты Российской Федерации» и отдельные законодательные акты Российской Федерации» (редакция от 25.12.2018) // СПС «Гарант».

6. Федеральный закон от 26.07.2017 N212-Ф3 «0 внесении изменений в части первую и вторую Гражданского кодекса Российской Федерации и отдельные законодательные акты Российской Федерации» (редакция от 01.06.2018) // СПС «Гарант».

7. Договорное и обязательственное право (общая часть): постатейный комментарий к статьям 307-453 Гражданского кодекса Российской Федерации. / Отв. ред. Карапетов А.Г.- М.: Статут, 2017. - 1120 с.

8. Суханов Е.А. Вещное право: Научно-познавательный очерк. - М.: Статут, 2017. - 560 c.

9. Российское гражданское право: Учебник в 2 т. / Отв. ред. Суханов Е.А. Т. 1: Общая часть. Вещное право. Наследственное право. Интеллектуальные права. Личные неимущественные права. - 4-е изд.- М.: Статут, 2016. — 958 с.

10. Бурдяк А.Я. Обеспеченность жильем в постсоветской России: неравенство и проблема поколений // Журнал исследований социальной политики.№ 13(2). - 2015.- - С. 273-288.

11. Варламова Т.П. Секьюритизация ипотечных активов как условия развития ипотечного жилищного кредитования в России // Информационная безопасность регионов. — № 18(1). - 2015.- С. 82-89.

12. Григорьев Л. Жилищное строительство и рынок недвижимости в период спада экономики // Бюллетень социально-экономического кризиса в России. - 2016. - 24 с.

13. Крючкова Е., Шаповалов А. От правительства ждут макростабильности или ипотечных субсидий. // Газета «Коммерсантъ».— № 26. — 13.02 .2019$.

14. Михайлов С.Н. Жилищный вопрос. Почему ипотечные облигации не востребованы у частных инвесторов // Сайт forbes.ru. [Электронный ресурс]. URL: https://www.forbes.ru/finansy-i-investicii/357805-bespoleznye-metry-pochemu-v-rossii-ne-vostrebovany-ipotechnye-obligacii (дата обращение 12.05.2021). 